\title{
A Study of Chromosomal Abnormality Patterns in Patients with Primary Amenorrhea in a Tertiary Care Referral Hospital
}

\section{ABSTRACT}

Introduction: Congenital absence of uterus, inability of the ovary to produce the eggs and any malformations of ovary, fallopian tube, uterus and adnexal tissue may lead to Primary Amenorrhea (PA). The genetic and chromosomal abnormalities are the main cause of PA. Endocrine causes like abnormal function of pituitary gland and hypothalamus also lead to PA. Other causes like stress, extreme physical activity and psychological causes or a combination of these causes may lead to delayed onset of menarche.

Aim: To study the frequency and type of chromosomal abnormalities in PA patients.

Materials and Methods: In the present descriptive study, subjects included patients referred with PA for chromosomal analysis to Sri Siddhartha Medical College Genetic Laboratory. Pedigrees with details were drawn and in-depth clinical evaluation and clinical information were obtained from all subjects.
Results: Of the 77 females with amenorrhea, 65 (84.4\%) had a normal karyotype $(46, \mathrm{XX})$ while $12(15.58 \%)$ had abnormal karyotype. The age group of the patients with PA ranged from 16-27 years. Mean age of PA was 21 years. In the present study, among 12 abnormal karyotyping patients 7 (58,3\%) patients showed $\mathrm{XY}$, sex reversal. This study also identified a $\mathrm{X}$ chromosome homogeneous monosomy, (Turner's) $45 X$ in one (8.3\%) case. Turner's mosaic $45, X / 46, X X$ in three cases (25\%), and one case (8.3\%) showed inversion 46, XX, inv (11), (P15q11).

Conclusion: A significant number of patients had sex chromosomal abnormalities; thus, early cytogenetic investigation is prudent to guide further management. Genetic counselling should include the risk of premature menopause for patients with Turner's syndrome and the use of hormonal replacement therapy, the risk of gonadal malignancy for patients with $X Y$ gonadal dysgenesis and the possibility of infertility in the future children of patients with mosaic Turner.

\section{INTRODUCTION}

Amenorrhea is the absence or abnormal ending of the menses [1]. PA is defined as the absence of menarche by the age of 14 years without the development of secondary sexual features or lack of menstruation by the age of 16 years, despite the existence of normal growth with the appearance of secondary sexual features [2]. There are many causes which lead to amenorrhea, like abnormal functioning of ovaries, anatomical malformation of uterus and vagina, endometritis and disturbances in sex hormones like excess of testosterone [3]. Amenorrhea is the sixth leading cause of female infertility as per the World Health Organisation (WHO) survey. Additionally, among general population amenorrhea affects $2-5 \%$ of all women in the child bearing age [4]. The World Health Organisation has estimated $15 \%$ of the human population as being infertile and amenorrhea as the sixth largest major cause of female infertility. About $2-5 \%$ of the women of child bearing age group are affected by amenorrhea [5].

Among the causes for PA, the most common cause is dysfunction of the gonads (50.4\%), followed by hypothalamic/pituitary disorders (27.8\%) and genito-urinary tract abnormalities (21.8\%) [1]. Amenorrhea may lead to anxiety, depression, and suicidal tendencies in the affected individuals. Abnormal functioning of ovaries can occur due to genetic and Chromosomal Anomalies (CA), which is the major cause for PA. Other causes like hypothalamic or pituitary problems in the brain and physical problems such as problems with reproductive organs that can prevent periods from starting and extreme physical or psychological stress, or a combination of these factors that can delay the onset of menstruation [6]. One of the main causes of PA is chromosomal abnormalities which varies between $15.9 \%$ and $63.3 \%[7,8]$. Many cytogenetic studies have been conducted to know the type of chromosomal abnormality and also to find out the frequency of its occurrence. The karyotyping is one standard procedure to find the incidence of CAs in PA. Determination of genetic factors is very important for diagnosis, genetic counselling, and further management. Cytogenetic studies show that the incidence of CAs in PA is 20\%-40\% [9,10].

There is a wide range of incidence of chromosomal abnormalities in studies conducted in India. Korgaonkar $\mathrm{S}$ et al., showed that the frequency of the numerical chromosomal changes (43.8\%) was high compared to structural aberrations (26.4\%) [11]. In another study, $16.21 \%$ cases had chromosomal abnormalities or karyotypes that involved sexual chromosomal numerical changes [12]. Thus, this study aimed to study the frequency and type of chromosomal abnormalities in PA.

\section{MATERIALS AND METHODS}

The present study was a descriptive study which was conducted in genetic laboratory, department of Anatomy, Sri Siddhartha Medical College, Tumkur, Karnataka, India for a period of three years from June 2016 to May 2019. Institutional Ethics Clearance was taken with no. SSMC/IEC-5/MAR-2016.

Inclusion criteria: The study subjects included patients referred with PA for chromosomal analysis to genetic laboratory.

Exclusion criteria: The patients who had congenital malformation of uterus, fallopian tube and patients who were not willing to participate in the study were excluded.

About 1-2 mL of heparinised peripheral venous blood sample was collected from each patient aseptically. About 750 microlitre of 
this blood was added to $8 \mathrm{~mL}$ of Roswell Park Memorial Institute (RPMI) culture media. To this 200 microlitre of phytohemagglutinin was added. This culture medium was incubated at 37 degrees for 72 hours under carbon dioxide incubator. On day three, harvesting was done by adding 80 microlitres of colchicine and then incubated for one hour. Then, this mixture was centrifuged for 10 minutes at $1000 \mathrm{rpm}$ and supernatant fluid was removed. To the pellet, hypotonic potassium chloride was added and total solution was made up to $8 \mathrm{~mL}$. Then this solution was incubated in water bath at $55^{\circ}$ for 10 minutes. Then the fixative was prepared in 1:3 ratio by adding acetic acid and methyl alcohol. This fixative was added to the solution and centrifuged for 10 minutes at $1000 \mathrm{rpm}$. This procedure was repeated for three times and then the pellet was collected and diluted with $1 \mathrm{~mL}$ fixative and finally dropped on to the slide. The slides were baked for 45 minutes at 90 degree in hot air woven. The slides were tryptinised and stained for Giemsa banding technique and finally these were analysed under Applied Scientific Instrumentation (ASI) microscope.

\section{STATISTICAL ANALYSIS}

The results were analysed using descriptive statistics through MS-Excel.

\section{RESULTS}

A total of 77 females with PA were evaluated for chromosomal abnormalities. Of the total, 65 (84.4\%) had a normal karyotype (46, $X X)$. The age group of the patients ranged from 16-27years. Mean age was 21 years.

Among 12 abnormal karyotyping patients, 7 (58.3\%) showed XY, sex reversal. Chromosomal analysis identified a $X$ chromosome homogeneous monosomy, (Turner's) $45, X$ in one (8.3\%) case. Turner's mosaic, $45, X / 46, X X$ in three cases (25\%), and one case (8.3\%) showed inversion, 46, XX, inv (11), (P15q11) [Table/Fig-1].

\begin{tabular}{|l|c|c|c|c|}
\hline $\begin{array}{l}\text { Serial } \\
\text { No. }\end{array}$ & Chromosomal abnormalities & Karyotype & $\begin{array}{c}\text { Number } \\
\text { of cases }\end{array}$ & $\begin{array}{c}\text { Frequency } \\
(\%)\end{array}$ \\
\hline 1 & Normal Karyotype & $46, X X$ & 65 & 84.4 \\
\hline 2 & Sex reversal & $46, X Y$ & 07 & 9.09 \\
\hline 3 & Monosomy X (Turner's) & $45 X$ & 1 & 1.29 \\
\hline 4 & Turners Mosaic & $45, X / 46, X X$ & 3 & 3.89 \\
\hline 5 & Chromosomal inversion & $\begin{array}{c}46, X X, \text { inv (11) } \\
(\mathrm{P} 15 \mathrm{q} 11)\end{array}$ & 1 & 1.29 \\
\hline
\end{tabular}

[Table/Fig-1]:Karyotype particulars of the subjects with Primary Amenorrhea $(\mathrm{PA})(\mathrm{N}=77)$

\section{DISCUSSION}

Amenorrhea stands as one of the major causes of female infertility affecting $2-5 \%$ of all women of child bearing age [4]. As revealed by previous studies pertaining to amenorrhea, approximately $40 \%$ of PA cases have been found to have genetic causes $[10,13]$. These can be single gene disorders or chromosomal disorders. However, chromosomal abnormalities contribute to the constitutional aetiology of amenorrhea [14]. Present study also showed that chromosomal abnormality sex reversal as the major cause of PA. In a study by Wong MSF and Lam STS, $20 \%$ chromosomal abnormalities were from sex reversal as the cause for PA [8]. In a study conducted by Akbar $S$ et al., $8.6 \%$ of the cases showed monosomy $X$ (Turner's $45 X$ ) and sex reversal was seen in $5.5 \%$ of the cases [15]. Vijayalakshmi $J$ et al., found $7.8 \%$ of the cases to be Monosomy X (Turner's $45 X$ ) and $5 \%$ each of sex reversal and Turners Mosaic 45, X/46, XX [16]. In a study conducted by Roy AK and Banerjee D, 33.3\% of the cases were Turners Mosaic 45, X/46, XX, 26.7\% were Monosomy $X$ (Turner's $45 X$ ) and sex reversal was seen in $3.3 \%$ cases [Table/Fig-2] [7,15-17].

\begin{tabular}{|c|c|c|c|c|c|c|}
\hline $\begin{array}{l}\text { Serial } \\
\text { No. }\end{array}$ & $\begin{array}{l}\text { Karyotype } \\
\text { results }\end{array}$ & $\begin{array}{l}\text { Present } \\
\text { study } \\
n=77\end{array}$ & $\begin{array}{l}\text { Wong } \\
\text { MSF and } \\
\text { Lam STS } \\
{[7] n=237}\end{array}$ & $\begin{array}{c}\text { Roy } \\
\text { AK and } \\
\text { Banerjee } \\
\text { D [17] } \\
n=60\end{array}$ & $\begin{array}{l}\text { Akbar } \\
\text { S et } \\
\text { al., [15] } \\
n=220\end{array}$ & $\begin{array}{c}\text { Vijayalakshmi } \\
\text { J et al., [16] } \\
n=140\end{array}$ \\
\hline 1 & $\begin{array}{c}\text { Normal } \\
\text { karyotype } \\
46, X X\end{array}$ & $\begin{array}{c}65 \\
(84.4 \%)\end{array}$ & $\begin{array}{c}179 \\
(75.5 \%)\end{array}$ & $\begin{array}{c}22 \\
(36.5 \%)\end{array}$ & $\begin{array}{c}176 \\
(80 \%)\end{array}$ & 101 (72.1\%) \\
\hline 2 & $\begin{array}{c}\text { Sex reversal } \\
46, X Y\end{array}$ & $\begin{array}{c}07 \\
(9.09 \%)\end{array}$ & 20 (8.4\%) & 2 (3.3\%) & 12 (5.5\%) & 07 (5\%) \\
\hline 3 & $\begin{array}{l}\text { Monosomy } \\
\text { X (Turner's) } \\
45 \mathrm{X}\end{array}$ & $\begin{array}{c}01 \\
(1.29 \%)\end{array}$ & 14 (5.9\%) & $\begin{array}{c}16 \\
(26.7 \%)\end{array}$ & 19 (8.6\%) & $11(7.8 \%)$ \\
\hline 4 & $\begin{array}{l}\text { Turners } \\
\text { Mosaic } 45 \text {, } \\
\text { X/46, XX }\end{array}$ & $\begin{array}{c}03 \\
(3.89 \%)\end{array}$ & 15 (6.3\%) & $\begin{array}{c}20 \\
(33.3 \%)\end{array}$ & $3(1.4 \%)$ & 07 (5\%) \\
\hline 5 & $\begin{array}{l}\text { Chromosomal } \\
\text { inversion 46, } \\
\text { XX, Inv (11), } \\
\text { (P15q11) }\end{array}$ & $\begin{array}{c}01 \\
(1.29 \%)\end{array}$ & - & - & 1 (0.45\%) & $01(0.7 \%)$ \\
\hline
\end{tabular}

\section{Limitation(s)}

Present study was conducted on a small number of patients.

\section{CONCLUSION(S)}

A significant number of study participants had sex chromosomal abnormalities, thus early cytogenetic investigation is prudent to guide further management. The patients with PA should be referred for genetic evaluation after excluding the non-genetic causes for PA. Genetic counselling should include the risk of premature menopause for patients with Turner's syndrome and the use of hormonal replacement therapy, the risk of gonadal malignancy for patients with $X Y$ gonadal dysgenesis and the possibility of infertility in the future children of patients with mosaic Turner.

\section{REFERENCES}

[1] Schorge JO, Schaffer JI, Halvorson LM, Hoffman BL, Bradshaw KD, Cunningham FG. Amenorrhea. In: Schorge JO, Schaffer Jl.editors. Williams Gynecology. New York, NY: McGraw Hill; 2008:1112-28.

[2] Speroff L, Glass RH, Kase NG. In: Clinical Gynecologic Endocrinology and Infertility. $6^{\text {th }}$ ed. USA: Lippincott Williams and Wilkins; Amenorrhea; 1999; 421-76.

[3] Rattanachaiyanont M, Kunathikom S, Angsuwattana S, Techatraisak K, Mekmahan O, Karavagul C, et al. Primary amenorrhoea: A retrospective study at Siriraj Hospital. J Med Assoc Thai. 1997;80(10):619-25.

[4] Dutta UR, Ponnala R, Pidugu VK, Dalal AB. Chromosomal abnormalities in amenorrhea: A retrospective study and review of 637 patients in south India. Arch Iran Med. 2013;16(5):267-70.

[5] World Health Organization, Special Programme of Research Development and Research training in Human Reproduction. 1985. 14th Annual report, Geneva. 114. pp. 119

[6] Pascal P, Leprieur E, Zenaty D, Thibaud E, Polak M, Frances AM, et al. Steroidogenic factor-1 (SF-1) gene mutation as a frequent cause of primary amenorrhea in 46, XY female adolescents with low testosterone concentration. Reprod. Biol. Endocrinol. 2010;8(28):01-06.

[7] Wong MSF, Lam STS. Cytogenetic analysis of patients with primary and secondary amenorrhea in Hong Kong: Retrospective study. Hong Kong Med J. 2005;11:267-72.

[8] Joseph A, Thomas IM. Cytogenetic investigation in 150 cases with complaints of sterility or primary amenorrhea. Hum Genet. 1982;61:105-09.

[9] Hunter TM, Heiman Diana MD. Amenorrhea: Evaluation and treatment. Am Fam Physician. 2006;73:1374-82.

[10] Rajangam S, Nanjappa L. Cytogenetic studies in amenorrhea. Saudi Med J. 2007;28:187-92.

[11] Seema K, Somprakash D, Vinayak K, Lily K, Babu RV. Clinical and cytogenetic profile of 490 cases of primary amenorrhea. JMSCR. 2018;6(7):487-94.

[12] Korgaonkar S, Walied KB, Neelam S Jamwal KS. Cytogenetic investigation of cases with primary amenorrhea in Jammu region of Jammu and Kashmir International Journal of Zoology and Research (IJZR). 2020;10(2):01-08.

[13] Seabright M. A rapid banding technique for human chromosomes. Lancet. 1971;2:971-72.

[14] Verma RS, Arvind B. Human chromosomes-principles and techniques. $2^{\text {nd }}$ ed. New York: McGraw-Hill Inc.; 1995.

[15] Akbar S, Mohammad V, Hossein A. Cytogenetic analysis of patients with primary amenorrhea in southwest of Iran. Iranian Journal of Pathology. 2010;5(3):121-25 
[16] Vijayalakshmi J, Teena K, Harpreet K, Andrea MF, Selvi R, Deepa PV, et al. Cytogenetic Analysis of Patients with Primary Amenorrhea. Int J Hum Genet. 2010;10(1-3):71-76.
[17] Roy AK, Banerjee D. Cytogenetic study of primary amenorrhoea. J Indian Med Assoc. 1995;93(8):291-92

\section{PARTICULARS OF CONTRIBUTORS:}

1. Associate Professor, Department of Anatomy, Sri Siddhartha Medical College, Sri Siddhartha Academy of Higher Education, Tumkur, Karnataka, India.

2. Professor and Head, Department of Anatomy, Sri Siddhartha Medical College, Sri Siddhartha Academy of Higher Education, Tumkur, Karnataka, India.

3. Consultant Clinical Geneticist, Department of Anatomy, Sri Siddhartha Medical College, Sri Siddhartha Academy of Higher Education, Tumkur, Karnataka, India.

4. Consultant Clinical Geneticist, Department of Anatomy, Sri Siddhartha Medical College, Sri Siddhartha Academy of Higher Education, Tumkur, Karnataka, India.

5. Research Associate, Department of Anatomy, Sri Siddhartha Medical College, Sri Siddhartha Academy of Higher Education, Tumkur, Karnataka, India.

\section{NAME, ADDRESS, E-MAIL ID OF THE CORRESPONDING AUTHOR:}

\section{Shivaleela,}

Associate Professor, Department of Anatomy, Sri Siddhartha Medical College,

Sri Siddhartha Academy of Higher Education, Tumkur-572107, Karnataka, India.

E-mail: drshivaleela83@yahoo.co.in

\section{AUTHOR DECLARATION:}

- Financial or Other Competing Interests: None

- Was Ethics Committee Approval obtained for this study? Yes

- Was informed consent obtained from the subjects involved in the study? Yes

- For any images presented appropriate consent has been obtained from the subjects.
PLAGIARISM CHECKING METHODS: [Jain Het al.]

- Plagiarism X-checker: Oct 06, 2020

- Manual Googling: Jan 05, 2021

- iThenticate Software: Mar 03, 2021 (10\%)
ETYMOLOGY: Author Origin

Date of Submission: Oct 05, 2020

Date of Peer Review: Dec 03, 2020

Date of Acceptance: Jan 11, 2021

NA 